\title{
DALIL-DALIL HUKUM YANG DIGUNAKAN DALAM FATWA DEWAN SYARIAH NASIONAL MAJELIS ULAMA INDONESIA NOMOR 40/DSN-MUI/X/2003 TENTANG PASAR MODAL SYARIAH
}

\author{
Masrina \\ Universitras Muhammadiyah Banjarmasin, Email : Masrina9911@gmail.com
}

\begin{abstract}
ABSTRAK
Penelitian ini dilatar belakangi oleh adanya beberapa dalil hukum yang digunakan oleh DSN-MUI dalam menetapkan Fatwa DSN-MUI No.40/DSN-MUI/X/2003 tentang Pasar Modal dan Pedomam Umum Penerapan Prinsip Syariah Bidang Pasar Modal tersebut. Masalah pokok yang menjadi fokus penelitian adalah analisis dalil-dalil hukum yang digunakan dalam Fatwa DSN-MUI tersebut sesuai dengan isi fatwa yang dimaksud. Dalil hukum yang dianalisis didalam penelitian dibatasi hanya pada dalil berupa ayat-ayat al-Quran, sedangan dalil yang lain tidak diteliti karena dalil al-Quran merupakan dalil yang pokok sementara dalil yang lain hanya tambahan. Metode penelitian yang digunakan didalam penelitian ini adalah metode penetian perpustakaan dengan pendekatan yuridis normatif yaitu mengkaji berdasarkan norma-norma hukum yang terdapat didalam ayat-ayat al-Quran yang dijadikan DSN-MUI sebagai dalil hokum menerapkan fatwa DSN-MUI No.40/DSN-MUI/X/2003 tentang Pasar Modal dan Pedomam Umum Penerapan Prinsip Syariah Bidang Pasar Modal. Sifat penelitian ini adalah deskriptif analitis dengan pendekatan kualitatif terhadap bahan hukum yang diperoleh. Dari hasil penelitian ini diketahui bahwa ada lima ayat al-Quran yang dijadikan DSN-MUI sebagai dalil hukum dalam menetapkan fatwa DSN-MUI No.40/DSN-MUI/X/2003 tentang pasar modal dan Pedomam Umum Penerapan Prinsip Syariah di Bidang Pasar Modal. Kelima ayat tersebut adalah (1. Q.S Al-Baqarah /2:275) (2. Q.S Al-Baqarah/2:278-279) (3. Q.S An-Nisa/4:29) (4. Q.S Al-Jumu'ah/62:10) (5. Q.S Al-Maidah/5:1). Setelah melalui analisis terhadap kelima ayat tersebut dapat disimpulkan bahwa penggunaan ayat-ayat ini untuk dalil hukum menetapkan fatwa DSN-MUI No.40/DSN-MUI/X/2003 tentang pasar modal dan Pedomam Umum Penerapan Prinsip Syariah diBidang Pasar Modal sudah tepat dan sesuai dengan materi atau isi dari fatwa tersebut.
\end{abstract}

Kata-kata kunci : Fatwa DSN-MUI; Istinbat Hukum; Dalil Hukum; Pasar Modal.

\section{ABSTRACT}

This research is motivated by the existence of several legal arguments used by the DSN-MUI in establishing the DSN-MUI Fatwa No.40 / DSN-MUI / X / 2003 concerning the Capital Market and General Guidelines for the Application of Sharia Principles in the Capital Market Sector. The main problem that becomes the focus of the research is the analysis of the legal arguments used in the DSN-MUI Fatwa in accordance with the content of the fatwa in question. The legal arguments analyzed in the study are limited to those in the form of verses of the Koran, while the other arguments 
are not examined because the arguments of the Koran are the main arguments while the others are only additional. The research method used in this research is the library research method with a normative juridical approach, which is to study based on the legal norms contained in the verses of the Koran which are used as the DSN-MUI as a legal argument applying the DSN-MUI fatwa No.40 I DSN- MUI / X / 2003 concerning Capital Market and General Guidelines for the Application of Sharia Principles in the Capital Market Sector. The nature of this research is descriptive analytical with a qualitative approach to the legal materials obtained. From the results of this study it is known that there are five verses of the Koran which are used by the DSN-MUI as legal arguments in establishing the DSN-MUI fatwa No.40 / DSN-MUI / X / 2003 concerning the capital market and General Guidelines for the Application of Sharia Principles in the Capital Market Sector. The five verses are (1. QS Al-Baqarah / 2: 275) (2. QS Al-Baqarah / 2: 278-279) (3. QS An-Nisa / 4: 29) (4. QS Al-Jumu'ah / 62: 10) (5. QS Al-Maidah / 5: 1). After going through the analysis of the five paragraphs, it can be concluded that the use of these verses for legal argument stipulates the DSN-MUI fatwa No.40 / DSN-MUI / X / 2003 concerning the capital market and the General Guidelines for the Application of Sharia Principles in the Capital Market Sector is appropriate and appropriate. with the material or content of the fatwa.

Keywords: Fatwa DSN-MUI; Legal Istinbat; Legal Proposals; Capital market.

\section{PENDAHULUAN}

Sistem ekonomi Islam adalah penerapan ilmu ekonomi dalam praktik sehari-hari bagi individu maupun kelompok masyarakat dalam rangka mengorganisir faktor produksi, distribusi, dan pemanfaatan barang dan jasa yang dihasilkan serta tunduk dalam peraturan perundangundangan Islam (Diana, 2012: 1). Al-Qur'an pada bidang ekonomi seperti halnya dalam bidang muamalat pada umumnya memberikan pedomanpedoman yang bersifat garis besar seperti membenarkan rezeki dengan jalan berdagang, melarang makan riba, melarang menghambur-hamburkan harta, perintah bekerja untuk mencari kecukupan nafkah dan sebagainya.

Perubahan ini mendorong adanya pemikiran-pemikiran baru yang umumnya dituangkan dalam bentuk undang-undang sebagai salah satu bentuk hukum literature hukum Islam. Pemikiran-pemikiran baru tentang hukum Islam juga sering dituangkan dalam fatwa-fatwa ulama dan keputusan-keputusan pengadilan agama. Masing-masing produk pemikiran hukum itu mempunyai ciri khasnya sendiri yang karenanya memerlukan perlakuan tersendiri pula. Fatwa dianggap sebagai materi hukum terbaru dan terlama yang relevan dengan kebutuhan masyarakat. Fatwa-fatwa ulama atau mufti sifatnya adalah kasuistik karena merupakan jawaban atas pertanyaan yang diajukan oleh peminta fatwa. Fatwa tidak 
mempunyai daya ikat, dalam arti bahwa si peminta fatwa tidak harus mengikuti isi maupun hukum fatwa yang diberikan kepadanya, tetapi fatwa biasanya cenderung bersifat dinamis karena merupakan respon terhadap perkembangan baru yang sedang dihadapi oleh masyarakat. Sifat tidak mengikatnya fatwa memberikan peluang bagi para mufti dalam berijtihad untuk memberikan jawaban alternative hukum yang sesuai dengan kebutuhan zaman.

Kemajuan dalam bidang ilmu pengetahuan dan teknologi serta perkembangan tatanan sosial kemasyarakatan, budaya, politik dan ekonomi akhir-akhir ini telah menyentuh seluruh aspek kehidupan. Perkembangan dan perubahan zaman tidak saja membawa berbagai kemudahan dan kebahagiaan, namun juga telah menimbulkan sebuah perilaku dan persoalan baru. Cukup banyak persoalan yang beberapa waktu lalu tidak pernah dikenal, bahkan tidak pernah terbayangkan, kini hal itu menjadi kenyataan. Pandangan Islam tentang hal tersebut boleh jadi telah termuat baik secara tersurat dan tersirat dalam sumber utama ajaran Islam, Al-Quran dan Hadis Nabi. Tidak tertutup pula kemungkinan bahwa hal-hal tersebut telah termuat dalam khazanah klasik karya para imam madzhab dan para ulama terdahulu, baik secara tegas ataupun dengan perumpamaan yang sesuai dengan kondisi dan perkembangan yang terjadi pada masa lalu.

Jika jawaban persoalan itu telah terkandung dalam Al-Quran dan Hadis maupun dalam khazanah klasik, permasalahannya tetap belum selesai sampai disitu, karena tidak semua orang dapat menelaah secara langsung, bahkan akan menjadi semakin kompleks jika mengenainya belum pernah dibicarakan sama sekali. Dalam menyikapi hal tersebut, para ulama berkewajiban untuk memahami kembali Al-Quran dan Hadis serta mengkaji ulang khazanah pemikiran Islam klasik dengan spirit yang baru. Ulama adalah penyambung lidah agama yang bertugas mendekatkan jarak masa lalu dengan masa kini dengan merekonstruksi kembali pemahaman khazanah Islam dengan cara yang telah mengena dengan kondisi kekinian sesuai dengan perkembangan zaman tanpa menyalahi kaidah ajaran agama Islam.

Majelis Ulama Indonesia (MUI) sebagai wadah musyawarah para ulama, zu'ama, dan cendekiawan muslim serta menjadi pengayom umat muslim seluruh Indonesia adalah lembaga yang berkompeten dalam 
menjawab dan memecahkan setiap masalah sosial keagamaan yang dihadapi oleh masyarakat luas. Sejalan dengan hal tersebut, sudah sewajarnya bila MUI sesuai dengan amanat musyawarah Nasional VI tahun 2000, senantiasa berupaya untuk meningkatkan kualitas peran dan kinerjanya, terutama dalam memberikan jawaban dan solusi keagamaan terhadap setiap permasalahan. Hal ini dimaksudkan untuk dapat memenuhi harapan umat Islam Indonesia yang semakin kritis dan tinggi kesadaraan keagamaannya. Sebagai wujud nyata dalam usaha untuk memenuhi harapan tersebut diatas, Majelis Ulama Indonesia memandang bahwa pedoman dan prosedur penetapan fatwa MUI yang ditetapkan melalui ijtima ulama komisi fatwa se-Indonesia melalui sidang pleno di Jakarta, tanggl 22 syawal 1424 H/16 Desember 2003 M, dipandang perlu disempurnakan. Atas dasar itu, majelis Ulama Indonesia perlu mengeluarkan pedoman baru yang memadai, cukup sempurna dan transparan terkait pedoman dan prosuder pemberian jawaban masalah keagamaan, dengan prinsip sistematis (tafshiliy), argumentative (berbijak pada dalil syar'i), kontekstual (waqi'iy), dan aplikatif (tathbiqy.)

Mekanisme dan proses keluarnya fatwa, secara teoritis MUI telah mempunyai aturan pedoman tata cara penerapan fatwa. Dalam pedoman fatwa dinyatakan bahwa suatu fatwa hanya dikeluarkan setelah terlebih dahulu mempelajari sumber-sumber hukum yang empat, yaitu Al-Quran, Sunnah, Ijma dan Qiyas. Tetapi dalam praktiknya ada yang langsung meneliti naskah fiqih klasik yang ada dan menganalogikan dengan masalah yang dibicarakan tanpa mempelajari terlebih dahulu ayat-ayat al-Qur'an dan hadits-hadits yang bersangkutan. Dengan telah berdirinya beberapa lembaga keuangan bank dan nonbank yang menampilkan semangat Islam, maka untuk memenuhi dan melindungi kepentingan masyakat, Majelis Ulama Indonesia pada tanggal 10 Februari 1999 membentuk sebuah dewan yang disebut Dewan Syariah Nasional, sejak berdirinya pada awal 1999 hingga sampai tahun 2017 ini sudah lebih 100 fatwa yang menyangkut berbagai jenis kegiatan keuangan, produk, dan jasa keuangan syariah (Eirdyaningsih, 2017: 34). Dewan Syariah Nasional bertugas untuk mengawasi dan mengarahkan lembaga-lembaga keuangan syariah untuk mendorong nilai-nilai ajaran Islam dalam kegiatan perekonomian dan keuangan. Dalam proses fatwanya diperkirakan terjadi modifikasi fiqih muamalah sehingga melahirkan produk-produk 
perbankan yang lebih mudah dalam operasionalnya yang dilandaskan pada fatwa ulama (Jaih, 2004:3).

Hubungan perekonomian merupakan suatu fitrah dan kecenderungan alami manusia sebagai makhluk yang memiliki fisik yang terbatas sehingga membuatnya tidak mampu untuk memenuhi segala kebutuhan jasmaniahnya seorang diri. Oleh karena itu, ia membutuhkan orang lain melalui berbagai macam transaksi muamalah untuk membantu memenuhi kebutuhan tersebut. Namun, tentu saja hubungan perekonomian ini harus diatur agar manusia terhindar dari transaksi ribawi ataupun garar yang diharamkan. Hal ini disebutkan dalam firmal Allah pada pengalan ayat Q.S Baqarah/2: 275 yang berbunyi:

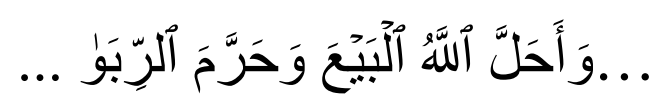

Islam memerintahkan agar umat selalu memproduktifkan harta bendanya. Bagi orang yang tidak dapat memproduktifkan hartanya, Islam mengajurkan untuk melakukan musyarakah atau mudharabah, yaitu dengan modal kerja sama. Jika pemilik modal tidak ingin mendapat risiko investasi, maka ia dapat menggunakan instrumen pinjaman (al-qardh), yaitu meminjamkan modal kepada pelaku bisnis tanpa upah laba apa pun dan tanpa terkena risiko apa pun. Secara mikro untuk kesejahteraan masyarakat sangat menguntungkan karena adanya pinjaman, maka perputaran ekonomi akan lebih cepat dan adanya komoditas peran dalam masyarakat. Faktor penggerak yang mendasar dalam aktivitas ekonomi adalah pemenuhan kebutuhan manusia. Kebutuhan manusia terpenuhi apabila tersedianya barang atau jasa hasil produksi. Dalam memenuhinya, manusia memiliki kemampuan yang berbeda-beda. Perbedaan ini antara lain disebabkan oleh adanya proses produksi, yang sangat terkait dengan faktor-faktor pendukungnya yang masih terbatas jumlah, termasuk modal (capital).

Ada tiga pertimbangan DSN-MUI menyebutkan fatwa tentang pasar modal ini. pertama, perkembangan ekonomi suatu Negara tidak terlepas dari pasar modal. kedua, pasar modal berdasarkan prinsip syariah tetap dikembangkan di lembaga Negara. Ketiga, umat Islam Indonesia memerlukan pasar modal yang aktivitasnya sejalan dengan prinsip syariah. Fatwa DSN hanya melihat pasar modal dari sudut barang yang diperjual belikan dan proses transaksi antara penjual dan pembeli yang harus sesuai 
dengan prinsip-prinsip syariah. Padahal dalam masalah pasar modal perlu juga diperhatikan dan diteliti perseroannya. Perseroan (perusahaan) antara dua orang atau lebih perlu mengikuti prinsip syariah, termasuk keharusan adanya akad, ijab dan qabul (kesepakatan untuk kerja sama) dan memproduktifkan harta. Dalam bidang ekonomi, Islam menempatkan self interest (maslahah al-fard) dan social interest (maslahah al-'ammah) sebagai jaminan dan keadilan ekonomi, jaminan sosial dan pemanfaatan modal ekonomi sebagai prinsip fundamental sistem ekonominya. Implikasi dari prinsip syariah ini mendukung berbagai kegiatan investasi dan ekonomi yang akan memberikan dampak positif pada ekonomi yang nyata berdasarkan keadilan sebagai investor dan pengelolahnya. Oleh itulah pihak yang berkepentingan atas ekonomi Islam tersebut membuat aturan yang bersifat fatwa untuk menghindari risiko penyalahgunaan hukum Islam. Salah satu aturan itu ialah Fatwa DSN-MUI No. 40/DSN-MUI/X/2002 tentang Pasar Modal dan Pedoman Umum Penerapan Prinsip Syariah di Bidang Pasar Modal.

\section{METODE PENELITIAN}

Metode penelitian yang digunakan didalam penelitian ini adalah metode penetian perpustakaan dengan pendekatan yuridis normatif yaitu mengkaji berdasarkan norma-norma hukum yang terdapat didalam ayat-ayat al-Quran yang dijadikan DSN-MUI sebagai dalil hokum menerapkan fatwa DSN-MUI No.40/DSN-MUI/X/2003 tentang Pasar Modal dan Pedomam Umum Penerapan Prinsip Syariah Bidang Pasar Modal. Sifat penelitian ini adalah deskriptif analitis dengan pendekatan kualitatif terhadap bahan hukum yang diperoleh. Tehtik pengolahan bahan hukum dengan menggunakan langkah-langkah normatif, kemudian memberi kode atau tanda pada bagian tertentu, yaitu pada Fatwa MUI yang berhubungan dengan Fatwa DSN-MUI No. 40/DSN-MUI/X/2003 tentang Pasar Modal dan Pedoman Umum Penerapan Prinsip Syariah Di Bidang Pasar Modal, dengan menggunakan buku/kitab-kitab yang menjadi sumber bahan hukum yang akan dikutip sebagai bahan hukum pokok, sebagaimana didiskripsikan apa adanya.

\section{HASIL DAN PEMBAHASAN}

1. Pengertian Fatwa, Mufti dan Mifta

Fatwa adalah sebuah lembaga atau perorangan yang diakui 
otoritasnya, disampaikan oleh seorang mufti atau ulama, sebagai tanggapan atau jawaban terhadap pertanyaan yang diajukan oleh peminta fatwa (mustafti) yang tidak mempunyai keterikatan. Dengan demikian peminta fatwa tidak harus mengikuti isi atau hukum fatwa yang diberikan kepadanya (Rachmat, 2000:40). Tindakan memberi fatwa disebut futya atau ifta, suatu istilah yang merujuk pada profesi pemberi nasihat. Orang yang memberi fatwa disebut mufti atau ulama, sedangkan yang meminta fatwa disebut mustafti. Peminta fatwa bisa perseorangan, lembaga ataupun siapa saja yang membutuhkannya.

Hukum berfatwa adalah fardu kifayah, kalau ada orang lain yang bisa memberi fatwa selain dirinya. Adapun kalau tidak ada orang lain yang bisa memberi fatwa dan masalah yang difatwakan itu cukup mendesak maka ia pun secara fardu'ain wajib memberi fatwa atas pristiwa itu. Oleh karena fatwa itu menyangkut masalah agama maka tidak sembarang orang bisa menduduki sebagai mufti syarat-syarat yang harus dimiliki oleh seorang mufti antara lain adalah:

a. Fatwanya harus didasarkan kepada kitab-kitab induk yang mutabar agar fatwa yang diberikan itu dapat diterima oleh penerima fatwa.

b. Apabila ia berfatwa berdasarkan qoul seseorang $a^{\prime}$ lim, maka ia dapat menunjukan dasar sumber pengambilan fatwanya itu, dengan demikian ia terhindar dari berbuat salah dan bohong.

c. Seorang mufti harus mengerti atau mengetahui berbagai macam pendapat ulama agar tidak terjadi kesalah fahaman antara ia dan penerima fatwanya.

d. Seorang mufti haruslah seorang alim yang memiliki kejujuran (Zen, 2009:213).

Mufti adalah orang yang diberi wewenang untuk menghasilkan fatwa dengan cara ijtihad (Ansori, 2017:138). Mufti ialah pemberi fatwa. Namun, mufti tidak mengeluarkan fatwanya kecuali apabila diminta dan persoalan yang diajukan kepadanya adalah persoalan yang bisa dijawabnya sesuai dengan pengetahuannya. Oleh sebab itu, mufti dalam menghadapi suatu persoalan hukum harus benar-benar mengetahui secara rinci kasus yang dipertanyakan. Sedangkan ifta' (memberikan penjelasan suatau masalah) adalah usaha memberikan penjelasan tentang hukum syara' oleh ahlinya kepada orang yang belum mengetahuinya. Sedangkan ciri-cirinya adalah sebagai berikut : 
a. Ia adalah usaha memberikan penjelasan.

b. Penjelasan yang diberikan itu adalah tentang hukum syara' yang diperoleh melalui hasil ijtihad.

c. Orang yang memberikan penjelasan itu adalah orang yang ahli dalam bidang yang dijelaskan itu.

d. Penjelasan itu diberikan kepada orang yang bertanya yang belum mengetahui hukumnya.

2. Sumber-Sumber Dalil Hukum Islam

a. Al-Quran

Secara etimologis, Al-Quran merupakan masdar dari kata kerja yang berarti bacaan atau yang tertulis. Secara terminologis (istilah) para ulama ushul fiqh diantaranya. Dari definisi ini dapat disimpulkan ciri-ciri khas Al-Quran, adalah kalam Allah yang diturunkan kepada Muhammad SAW, maka tidak dinamakan Al-Quran, seperti Zabur, Taurat, dan Injil. Ketiga kitab yang disebut terakhir ini adalah kalam Allah, tetapi bukan diturunkan kepada Muhammad SAW, karenanya tidak dinamakan Al-Quran. Bukti bahwa Al-Quran adalah kalam Allah adalah kemu'jizatan yang dikandung Al-Quran itu sendiri, dari struktur bahasa isyarat-isyarat ilmiah yang dikandungnya, ramalan-ramalan masa depan yang diungkapkan Al-Quran.

b. As Sunnah

Secara terminologi, sunnah bisa dilihat dari tiga bidang ilmu, yaitu ilmu hadits, ilmu fiqh, dan ushul fiqh. Sunnah menurut para ahli hadits identik dengan hadits, yaitu seluruh yang disandarkan kepada Nabi Muhammad SAW, baik perkataan, perbuatan, maupun ketetapan atau sifatnya sebagai manusia biasa, akhlaknya, apakah itu sebelum maupun setelah diangkat menjadi Rasul. Sunnah menurut ahli ushul fiqh adalah segala yang diriwayatkan dari Nabi SAW berupa perbuatan, perkataan, dan ketetapan yang berkaitan dengan hukum.

c. Ijma'

Ijma' menurut istilah para ahli ushul figh adalah: kesepakatan seluruh para mujtahid dikalangan ummat Islam pada suatu masa setelah Rasulullah SAW wafat, terhadap hukum syara' tentang suatu masalah atau suatu kejadian. Ijma' adalah kesepakatan para ulama 
dalam menetapkan suatu hukum hukum dalam agama berdasarkan Al-Qur'an dan Hadis dalam suatu perkara yang terjadi (Rahman,2010: 145-147). Ijma' dapat terwujud apabila terdapat unsur-unsur/ rukun.

1) Adanya kesepakatan sejumlah mujtahid pada suatu masa tentang suatu peristiwa yang terjadi.

2) Kesepakatan para mujtahid itu harus berasal dari semua tempat dan golongan.

3) Kesepakatan para mujtahid itu harus nyata, baik dinyatakan dengan lisan maupun dapat dilihat dalam perbuatan.

4) Kesepakatan itu adalah kesepakatan yang bulat dari seluruh mujtahid.

Keputusan hukum dalam fatwa DSN-MUI nomor 40/DSN-MUI /X/2003 tentang Pasar Modal dan Pedoman Umum di Bidang Pasar Modal terdiri dari tujuh bab yang memuat delapan pasal. Pada bab pertama membahas tentang ketentuan umum yang terdiri dari:

1. Pasar modal adalah kegiatan yang bersangkutan dengan Penawaran Umum dan perdagangan Efek, Perusahaan Publik yang berkaitan dengan Efek yang diterbitkannya, serta lembaga dan profesi yang berkaitan dengan Efek.

2. Emiten adalah Pihak yang melakukan Penawaran Umum.

3. Efek syariah adalah efek sebagaimana dimaksud dalam peraturan perundang-undangan di bidang Pasar Modal adalah surat berharga yang akad, pengelolaan perusahaannya, maupun cara penerbitannya memenuhi Prinsip-prinsip Syariah.

4. Shariah Compliance Officer (SCO) adalah Pihak atau pejabat dari suatu perusahaan atau lembaga yang telah mendapat sertifikasi dari DSN-MUI dalam pemahaman mengenai Prinsip-prinsip Syariah di Pasar Modal.

5. Pernyataan kesesuaian Syariah adalah pernyataan tertulis yang dikeluarkan oleh DSN-MUI terhadap suatu Efek Syariah bahwa Efek tersebut sudah sesuai dengan Prinsip-prinsip Syariah.

6. Prinsip-prinsip syariah adalah prinsip-prinsip yang didasarkan atas ajaran Islam yang penetapannya dilakukan oleh DSN-MUI, baik ditetapkan dalam fatwa ini maupun dalam fatwa terkait lainnya. 
Bab kedua dalam keputusan DSN-MUI ini memuat mengenai prinsip-prinsip syariah di bidang pasar modal, yaitu:

1. Pasar Modal beserta seluruh mekanisme kegiatannya terutama mengenai emiten, jenis efek yang diperdagangkan dan mekanisme perdagangannya dipandang telah sesuai dengan syariah apabila telah memenuhi prinsip-prinsip syariah.

2. Suatu efek dipandang telah memenuhi prinsip-prinsip syariah apabila telah memperoleh ernyataan Kesesuaian Syariah.

Prinsip syariah yang dimaksud tidak dipaparkan secara jelas dan terperinci tetapi hanya menetapkan harus sesuai dengan syariah. Bab tiga dan berikutnya dalam fatwa DSN-MUI ini mengulas tentang pengertian dan kriteria emiten (emitent) atau perusahaan publik (umum) yang menerbitkan saham syariah. Menurut kriteria dalam bab ini yang bertentangan dengan syariah Antara lain ialah jenis usaha, produk barang dan jasa yang diberikan dan akad serta cara pengelolaan perusahaan emiten atau perusahaan publik yang menerbitkan efek (stock) syariah tidak boleh bertentangan dengan prinsip-prinsip syariah yaitu yang mengandung unsur dharar, riba, maysir, risywah, maksiat dan kezaliman, makanan dan minuman yang haram, harga pasar tidak layak, penyedia barang-barang atau jasa yang merusak moral dan bersifat mudharat, dan investasi padaemiten yang pada saat transaksi tingkat (persentase) utang perusahaan kepada lembaga keuangan ribawi lebih dominan dari modalnya.

Sumber hukum dalil Al-Quran yang digunakan Q.S Al-Baqarah/2: 275 ayat ini menjelaskan tentang jual beli adalah halal dan riba adalah haram, termasuk juga dalam pasar modal dimana transaksi ini mencakup transaksi muamalah dalam jual beli. Dalam dalil selanjutnya juga menjelaskan tentang perintah meninggalkan riba yaitu pada Q.S Al-Baqarah/2:278-279, ayat tersebut berhubungan dengan pasar modal syariah dalam menerapkan prinsip-prinsip pasar modal yang sesuai dengan syariah. Ayat selanjutnya Q.S An-Nisa/4:29 ayat ini menerangkah bahwa janganlah memakan harta sesamamu dengan jalan yang batil. Sebagaimana tersebut dalam fatwa DSN ini, pelaksanaan transaksi saham harus dilakukan menurut prinsip kehati-hatian serta tidak dibolehkan untuk melakukan spekulasi dan manipulasi yang didalamnya mengandung unsur gharar, riba dan 
maysir. Transaksi-transaksi seperti ini meliputi: najsy yaitu melakukan penawaran palsu, bay'al-ma'dum yaitu melakukan penjualan atas barang (saham syariah) yang belum dimiliki (short selling). Q.S Al-Jumu'ah/62:10 Ayat ini tidak secara spesifik menunjukan kepada hukum bertransaksi dipasar modal, tetapi secara umum ayat ini menunjukan bahwa orang yang telah melaksanakan kewajiban ibadah berupa shalat jum'at diperintahkan untuk keluar mencari rezki karunia Allah SWT termasuk dalam transaksi pasar modal dibursa efek.

Q.S Al-Maidah/5:1 ayat ini menerangkan tentang Sempurnakanlah berbagai bentuk akad (janji, kontrak) yang telah kamu akadkan dengan Allah, atau antara kamu dengan dirimu sendiri, atau antara kamu dengan sesama manusia. Baik berupa perintah maupun larangan syara' atau akad diantara kamu, seperti halnya dalam kontrak pasar modal syariah. Dari hasil penelitian ini diketahui bahwa ada lima ayat Al-Quran yang dijadikan DSN-MUI sebagai dalil hukum dalam menetapkan Fatwa DSN-MUI No.40/DSN-MUI/X/2003 tentang Pasar Modal dan Pedoman Umum Penerapan Prinsip Syariah di Bidang Pasar Modal. Kelima ayat tersebut adalah (1) Q.S Al-Baqarah/2:275, (2) Q.S Al-Baqarah/2:278-279, (3) Q.S An-Nisa/4:29, (4) Q.S Al-Jumu'ah/62:10,(5) Q.S Al-Maidah/5:1. Setelah melakukan analisis terhadap kelima ayat tersebut dapat disimpulkan bahwa pengunaan ayat-ayat ini untuk dalil hukum penetapan Fatwa DSN-MUI No.40/DSN-MUI/X/2003 tentang Pasar Modal dan Pedoman Umum Penerapan Prinsip Syariah di Bidang Pasar Modal sudah tepat dan sesuai dengan materi atau isi dari fatwa tersebut.

\section{SIMPULAN}

Berdasarkan uraian yang telah dikemukakan pada bab-bab terdahulu, maka penulis dapat menarik kesimpulan mengenai Fatwa DSN-MUI No.40/DSN-MUI/X/2003 tentang Pasar Modal dan Pedomam Umum Penerapan Prinsip Syariah Bidang Pasar Modal bahwa ijtihad kolektif dan keputusan DSN-MUI tentang pasar modal dan Pedomam Umum Penerapan Prinsip Syariah Bidang Pasar Modal kurang luas dan mendalam dalam melihat masalah darar, gharar, riba, maysir, riswah, maksiat dan kezhalilman, ini disebabkan oleh pemahaman terhadap masalah (tasawwur al-masalah) dalam fatwa mengenai pasar modal kurang mendalam. Fatwa DSN-MUI hanya melihat pasar modal dari sudut barang 
yang diperjual belikan dan proses transaksi Antara pihak penjual dan pembeli yang harus sesuai dengan prinsip-prinsip syariah. Padahal dalam masalah pasar modal perlu juga diperhatikan dan diteliti perseroannya.

Sumber hukum dalil Al-Quran yang digunakan Q.S Al-Baqarah/2: 275 ayat ini menjelaskan tentang jual beli adalah halal dan riba adalah haram, termasuk juga dalam pasar modal dimana transaksi ini mencakup transaksi muamalah dalam jual beli. Dalam dalil selanjutnya juga menjelaskan tentang perintah meninggalkan riba yaitu pada Q.S Al-Baqarah/2:278-279, ayat tersebut berhubungan dengan pasar modal syariah dalam menerapkan prinsip-prinsip pasar modal yang sesuai dengan syariah. Ayat selanjutnya Q.S An-Nisa/4:29 ayat ini menerangkah bahwa janganlah memakan harta sesamamu dengan jalan yang batil. Sebagaimana tersebut dalam fatwa DSN ini, pelaksanaan transaksi saham harus dilakukan menurut prinsip kehati-hatian serta tidak dibolehkan untuk melakukan spekulasi dan manipulasi yang didalamnya mengandung unsur gharar, riba dan maysir. Transaksi-transaksi seperti ini meliputi: najsy yaitu melakukan penawaran palsu, bay'al-ma'dum yaitu melakukan penjualan atas barang (saham syariah) yang belum dimiliki (short selling).

Q.S Al-Jumu'ah/62:10 Ayat ini tidak secara spesifik menunjukan kepada hukum bertransaksi dipasar modal, tetapi secara umum ayat ini menunjukan bahwa orang yang telah melaksanakan kewajiban ibadah berupa shalat jum'at diperintahkan untuk keluar mencari rezki karunia Allah SWT termasuk dalam transaksi pasar modal dibursa efek. Q.S Al-Maidah/5:1 ayat ini menerangkan tentang Sempurnakanlah berbagai bentuk akad (janji, kontrak) yang telah kamu akadkan dengan Allah, atau antara kamu dengan dirimu sendiri, atau antara kamu dengan sesama manusia. Baik berupa perintah maupun larangan syara' atau akad diantara kamu, seperti halnya dalam kontrak pasar modal syariah. Dari hasil penelitian ini diketahui bahwa ada lima ayat Al-Quran yang dijadikan DSN-MUI sebagai dalil hukum dalam menetapkan Fatwa DSN-MUI No.40/DSN-MUI/X/2003 tentang Pasar Modal dan Pedoman Umum Penerapan Prinsip Syariah di Bidang Pasar Modal. Kelima ayat tersebut adalah (1) Q.S Al-Baqarah/2:275, (2) Q.S Al-Baqarah/2:278-279, (3)Q.S An-Nisa/4:29, (4) Q.S Al-Jumu'ah/62:10,(5) Q.S Al-Maidah/5:1. Setelah melakukan analisis terhadap kelima ayat tersebut dapat disimpulkan bahwa pengunaan ayat-ayat ini untuk dalil hukum penetapan Fatwa 
DSN-MUI No.40/DSN-MUI/X/2003 tentang Pasar Modal dan Pedoman Umum Penerapan Prinsip Syariah di Bidang Pasar Modal sudah tepat dan sesuai dengan materi atau isi dari fatwa tersebut

\section{DAFTAR RUJUKAN}

Amirudin, Zen, (2009), Ushul Fiqih, Yogyakarta,Teras

Burhanuddin,(2019)., Pasar Modal Syariah (Tinjauan Hukum), Yogyakarta: UII Press,

Eirdyaningsih, (2017) Bank Dan Asuransi Islam Di Indonesia, Jakarta: Kencana,.

Fajar, Dewata Nur Mukti dan Yulianto Ahmad, (2010).Dualisme Penelitian Hukum Normatif dan Empiris,Yogyakarta: Pustaka Pelajar,

Hidayat, Taufik Racmat, (2000), Almanak Alam Islami, Pustaka Jaya: Jakarta..

Kamil, Ahmad dan M. Fauzan, (2017) Kitab Undang-Undang Hukum Perbankan dan Ekonomi Syariah, Jakarta: Kencana,

Hooker \& Amin Saikal (2014) et al, Islamic Perspektives on The New Millenium, Singapore: ISEAS Publication,.

Manan, Abdul, (2019) Aspek Hukum Dalam Penyelenggaraan Investasi Pasar Modal Syariah Indonesia, Jakarta: Perdana Memia Group,

Mubarok, Jaih, (2004), Perkembangan Fatwa Ekonomi Syariah di Indonesia, Bandung: Pustaka bani Quraisy,.

Moloeng, Lexy J, (2004). Metode Penelitian Kualitatif, Bandung: Rosdakarya, Nur, Diana, (2012).Ilfi, Hadits-Hadist Ekonomi, Malang UIN-Maliki Press, Sholeh, Ni'am Asrorun, (2016). Metodelogi Penetapan Fatwa MUI, Erlangga, Jakarta:

Shalih, Syaikh bin Al-Fauzan, (2008): Ummu Abdullah, Forbidden Business Transaction in Islam, Maktabah Raudhotul Muhibbin,.

Sugiyono, (2009).Memahami Penelitian Kualitatif, Bandung: CV. Alfabeta, 2 Suhendi, Hendi, (2002) .fiqih muamalah, Jakarta: PT. Raga grafindo persada, Zuriah, Nurul, (2007) Metodologi Penelitian Sosial dan Pendidikan: Teori-Aplikasi, Jakarta: Bumi Aksara,. 